\title{
SISTEM PENDETEKSI PLAGIARISME UNTUK TUGAS AKHIR MAHASISWA DI UNIVERSITAS BINA NUSANTARA: STUDI PENDAHULUAN
}

\author{
${ }^{1}$ Endang Ernawati; ${ }^{2}$ Anindito; ${ }^{3}$ Robertus Nugroho Perwiro Atmojo \\ ${ }^{1}$ English Departement, Faculty of Humanities, BINUS University \\ Jln. Kemanggisan Ilir III No. 45, Kemanggisan - Palmerah, Jakarta 11480 \\ ${ }^{2,3}$ School of Information Systems, BINUS University \\ Jln. K.H. Syahdan No. 9, Palmerah, Jakarta Barat 11480 \\ ernaw@binus.edu'; Anindito@binus.edu²; robertus.atmojo@gmail.com³
}

\begin{abstract}
Article functioned as a preliminary study for the research on plagiarism happened in student's thesis S1 in Bina Nusantara University and how to overcome this cases by a prevention procedure approved by the students, lecturers, departments, and other supporting units. The preliminary study was done by library research, finding some plagiarism cases, model, the way to prevent the case, and the sanction and punishment related to plagiarism. Results of this library research used for compiling questionnaire that will be contributed to students, thesis advisors, thesis judges, and the departments to get the real condition of plagiarism practices, prevention actions, and some input to support the next research.
\end{abstract}

Keywords: plagiarism detection, thesis S1

\begin{abstract}
ABSTRAK
Artikel menjelaskan studi pendahuluan untuk membuat model sistem pendeteksi plagiarisme untuk tugas akhir mahasiswa S1 di Universitas Bina Nusantara, termasuk usaha pencegahan, yaitu pembuatan prosedur yang disetujui oleh mahasiswa, dosen pembimbing, jurusan, dan unit terkait lain yang menangani tugas akhir mahasiswa. Berdasarkan perolehan studi literatur tentang berbagai kasus plagiarisme, model, dan cara pencegahan, maka disusun kuesioner yang akan dibagikan kepada mahasiswa, dosen pembimbing, dosen penguji, dan jurusan untuk mendapatkan gambaran yang nyata tentang tindak plagiarisme yang terjadi, upaya yang telah dilakukan, dan beberapa masukan untuk kelangsungan penelitian selanjutnya.
\end{abstract}

Kata kunci: deteksi plagiarisme, tugas akhir 


\section{PENDAHULUAN}

Kasus plagiarisme sedang marak di Indonesia beberapa tahun terakhir ini (Siswadi, 2012; Ramadhanny, 2010). Plagiarisme tidak hanya dilakukan oleh pelajar tetapi juga mahasiswa; bahkan mahasiswa pascasarjana dan para pendidik perguruan tinggi di negara maju pun tidak terlepas dari plagiarisme (Chao, Wilhelm, \& Neureuther, 2009). Permasalahan yang diteliti adalah usaha untuk mencegah plagiarisme, yaitu pengembangan sistem pendeteksi plagiarisme bagi mahasiswa dan dosen, karena mereka berfungsi sebagai pengguna dan sekaligus penghasil informasi/pengetahuan ilmiah. Artikel ini merupakan studi awal, yaitu studi pustaka sebagai acuan untuk penelitian selanjutnya.

Mulyana (2010) yang telah melakukan penelitian tentang pencegahan tindak plagiarisme dalam penulisan skripsi di Jurusan Bahasa dan Sastra Jawa, Universitas Negeri Yogyakarta telah menyimpulkan bahwa tindak plagiarisme yang telah dilakukan mahasiswa dalam penulisan skripsi adalah dalam bentuk duplikasi, termasuk duplikasi judul, duplikasi isi skripsi, duplikasi teori, duplikasi data, dan duplikasi referensi. Tindakan pencegahan yang dilakukan untuk menghindari plagiarisme ini adalah (1) mengembalikan atau merevisi skripsi; (2) mengharuskan pengutipan sumber primer; dan (3) membatalkan karya tulis. Jadi artikel ini lebih menekankan sanksi akademik dan moral untuk mencegah plagiarisme.

Selanjutnya Mulyana (2010) juga mengatakan bahwa modus tindak plagiarisme karya tulis ilmiah pada umumnya dilakukan dengan: (1) menyalin karya orang lain; (2) membonceng karya orang lain; (3) mengubah karya orang lain; (4) dibuatkan orang lain; dan (5) membeli karya orang lain. Peneliti juga setuju dengan pendapat penulis artikel ini, yaitu praktik plagiarisme ini sebetulnya sangat tidak menghargai karya orang lain, tidak percaya kepada kemampuan sendiri, dan merendahkan nilai kejujuran sendiri.

Kemajuan dunia internet juga memiliki sisi negatif dan positif terhadap tindakan plagiarisme. Sisi negatif adalah kesempatan melakukan plagiarisme akan makin mudah dengan adanya akses terhadap jutaan artikel ilmiah. Sedangkan sisi positif adalah internet mampu menjadi jembatan untuk mengecek apakah artikel yang yang ada sama atau berbeda dengan artikel yang telah dipublikasikan orang lain.

Ada berbagai macam cara mencegah praktik plagiarisme di tanah air, di antaranya adalah (a) menumbuhkan integritas mahasiswa, sehingga mereka jujur dalam melakukan kajian ilmiah; (b) meningkatkan fungsi dan peran pembimbing skripsi/penelitian, karena penelitian mahasiswa juga merupakan pertaruhan karier dari si pembimbing; dan (c) menggunakan software antiplagiarisme (Wijaya, 2010).

Salah satu fokus Binus 2013 adalah “content \& knowledge sebagai aset”, yaitu pengembangan hasil riset dan publikasi sebagai pengayaan konten. Konten yang dimaksud di Binus adalah repositori, yang juga merupakan penulisan berbasis penelitian, misalnya skripsi, tesis, disertasi, laporan penelitian, studi kasus, paket informasi, artikel, dan buku. Sebagai konten Universitas, aspek orisinalitas, dalam arti pengakuan terhadap karya orang lain dengan melakukan kutipan dan penulisan daftar pustaka, di samping ide sendiri yang asli, harus dipertahankan.

Masalah yang dibahasan dalam penelitian adalah (1) bagaimana tindak plagiarisme dipahami dan pernah dilakukan oleh mahasiswa di Universitas Bina Nusantara; dan (2) bagaimana prosedur dan pedoman penelitian dilakukan serta sejauh mana dampaknya terhadap tindak plagiarisme di Universitas Bina Nusantara? Sementara tujuan penelitian adalah (1) mengetahui tindak plagiarisme yang dilakukan mahasiswa di Universitas Bina Nusantara; dan (2) mengetahui prosedur dan pedoman 
penulisan skripsi serta sejauh mana dampaknya terhadap tindakan plagiarisme di Universitas Bina Nusantara.

\section{Tinjauan Pustaka}

Kementerian Pendidikan Nasional (2010) memberikan definisi plagiat sebagai perbuatan secara sengaja atau tidak sengaja dalam memperoleh atau mencoba memperoleh kredit atau nilai untuk suatu karya ilmiah, dengan mengutip sebagian atau seluruh karya dan/atau karya ilmiah pihak lain yang diakui sebagai karya ilmiahnya, tanpa menyatakan sumber secara tepat dan memadai. Sedangkan Moeliono (ed) dalam KBBI (1988:60) menyatakan: "Plagiarisme adalah pengambilan karya orang lain, dan dipublikasikan sebagai karya miliknya.” Rendahnya integritas akademik menyebabkan seseorang meninggalkan nilai-nilai kejujuran, mengabaikan kehormatan dan cenderung untuk bertindak curang serta memandang rendah pada kecerdasan orang lain (Yahya, 2011).

Berdasarkan pengertian tentang plagiarism, maka perlu dibuat sistem pendeteksi plagiarisme untuk mengenali jenis plagiarisme yang telah dilakukan. Salah satu sistem deteksi plagiarisme dihasilkan oleh Meyer zu Eissen, Stein, \& Kulig (2007) yang bisa dilihat pada Gambar 1 berikut.

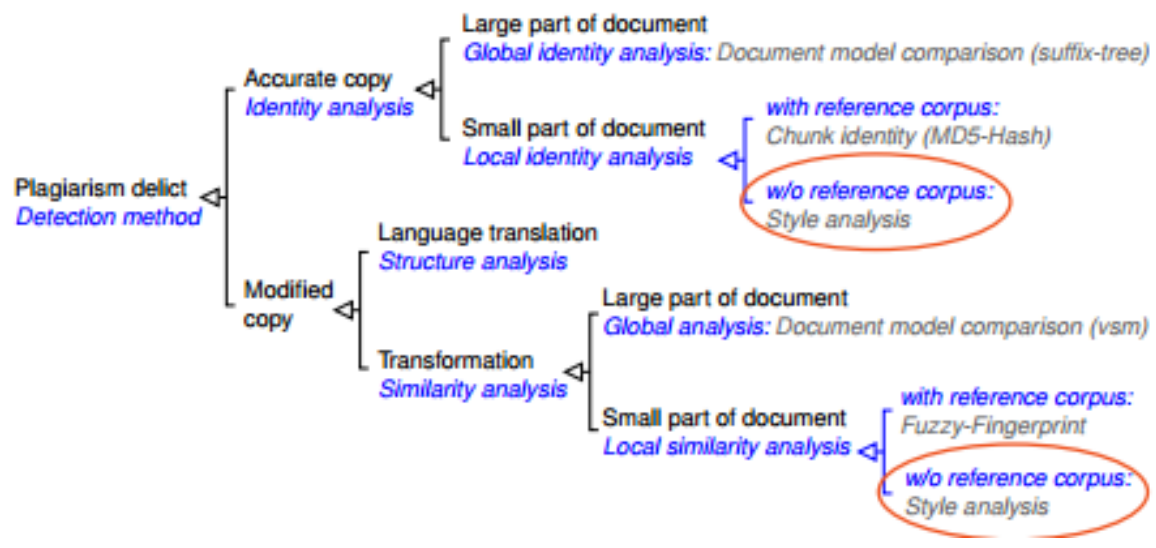

Gambar 1 Deteksi Plagiarisme

(Meyer zu Eissen, Stein, \& Kulig, 2007)

Sistem deteksi plagiarisme menurut Meyer zu Eissen, Stein, \& Kulig (2007) terdiri dari accurate copy dan modified copy. Accurate copy dimaksudkan sebagai perbandingan persis dengan dokumen model komparasi, misalnya basis data skripsi, tesis, dan artikel yang disimpan di Perpustakaan (LKC). Selanjutnya, modified copy terdiri dari language translation sebagai struktur analisis dan transformation sebagai analisis kesamaan. Dalam penelitian ini uji kesamaan (accurate copy) dilakukan dari dokumen yang kecil (small part of document) dan dokumen yang besar (large part of document), terhadap basis data tugas akhir dan karya ilmiah yang ada di Universitas Bina Nusantara sebagai reference corpus.

Banyak penelitian yang telah dilakukan untuk mengembangkan sistem deteksi plagiarisme di Indonesia (Salmuasih, 2013; Nugroho, 2011; Kurniawati, Puspitodjati, \& Rahman, 2010; Purwitasari, Kusmawan, \& Yuhana, 2011). Penelitian ada yang ditujukan untuk kepentingan khusus, misalnya pengecekan source code (Liliana, Budhi, Wibisono, \& Tanojo, 2012). Selain itu, ada juga yang meneliti tentang pengecekan plagiarisme cross language (Alfikri \& Purwarianti, 2012). Akan tetapi, belum ada penelitian terhadap pengembangan sistem deteksi plagiarisme terhadap dokumen yang sudah ada. Selain itu juga, penelitian yang ada sebelumnya bersifat teoretis sehingga tidak mudah diterapkan atau digunakan di institusi lain. 
Wibowo (2010) menjelaskan penelitiannya yang bertujuan untuk menguraikan arti dan dampak plagiarisme, sanksi bagi pelaku, serta upaya pencegahan dan penanggulangan plagiarisme. Beberapa cara memperkecil risiko plagiarisme yang diusulkan adalah dengan melakukan upaya pencegahan secara sistem antara lain menciptakan iklim pendidikan yang kondusif, menghargai tulisan orang lain, pelatihan pembuatan parafrasa, rujukan, penulisan referensi yang benar, menciptakan peranti lunak untuk pengecekan duplikasi artikel, dan rajin bertanya untuk mendapatkan pengarahan.

Penelitian lain dilakukan oleh Mulyana (2010) menggunakan metode pemecahan masalah dengan pendekatan proses yang dilakukan secara eksplorasi, yaitu pengungkapan kasus dalam lingkup dan persoalan tertentu. Penelitian dilakukan selama 6 bulan (Mei-Oktober 2008) di Jurusan PBD, Fakultas Bahasa dan Sastra, Universitas Negeri Yogyakarta. Pengumpulan data dilakukan dengan mendokumentasikan dan mengklasifikasi draft proposal tugas akhir skripsi (TAS) yang masuk ke jurusan. Draft dianalisis berdasarkan duplikasi yang ada, yang masuk dalam plagiarisme. Topik TAS yang terindikasi plagiarisme dijadikan data penelitian untuk mendapatkan gambaran kasus yang kemudian dianalisis secara deskriptif kualitatif. Metode deskriptif digunakan untuk mengidentifikasi topik dan substansi tugas akhir. Dengan menelaah sejumlah data yang ada ditemukan kemiripan dan diakukan pendekatan dengan teori Eliot (1990). Hasil menunjukkan bahwa terjadinya gejala plagiarisme disebabkan oleh faktor internal yang berkaitan dengan watak dan karakter mahasiswa; dan faktor eksternal yang berkaitan dengan kondisi dan kesempatan. Praktik plagiarisme yang ditemui adalah duplikasi substansi, duplikasi teori, duplikasi data, dan duplikasi referensi. Tindakan yang dilakukan adalah membatalkan atau merevisi TAS, mengharuskan pengutipan sumber primer, dan membatalkan TAS.

\section{METODE}

Studi pendahuluan menggunakan metode kualitatif dengan tipe studi pustaka. Selanjutnya, analisis kebutuhan diperoleh melalui survei terstruktur yang dilakukan terhadap empat bagian di Universitas Bina Nusantara, yaitu Bagian Akademik (SRSC), Bagian Library \& Knowledge Center (LKC), Research Office, dan Jurusan (pembimbing dan penguji). Survei dilakukan dengan melakukan wawancara terstruktur. Wawancara terstruktur terdiri dari pengajuan daftar pertanyaan yang sudah dibuat sebelumnya untuk menganalisis kebutuhan informasi yang terkait dengan plagiarisme di dalam kegiatan operasional mereka masing-masing.

Selanjutnya, data skripsi yang tersedia dianalisis agar nantinya dapat digunakan sebagai sumber data plagiarisme. Skenario paling awal untuk pembentukan basis data adalah dengan melakukan upload data skripsi, tesis, disertasi, dan segala karya ilmiah yang telah beredar dalam lingkup Universitas Bina Nusantara ke dalam format digital (contoh: format .doc, .docx, LaTex, .pdf; dll) ke repositori online seperti eprints.binus.edu.

Skenario pembentukan basis data online selanjutnya, yang paling memungkinkan adalah diperlukan kerja sama dari instansi untuk mengeluarkan sebuah peraturan/regulasi kepada tiap mahasiswa yang telah dinyatakan lulus sidang pendadaran skripsi, tesis, maupun disertasi dan telah mendapatkan Lembar Pengesahan untuk melakukan publikasi dengan cara upload data ke dalam sebuah weblog/website yang dapat diakses online. Dengan begitu data ilmiah para mahasiswa dapat diindeks oleh robot mesin pencari seperti Google, Bing, Yahoo, Baidu, dan lain-lain. Contoh tampilan sistem pendeteksi adalah Gambar 2 berikut. 


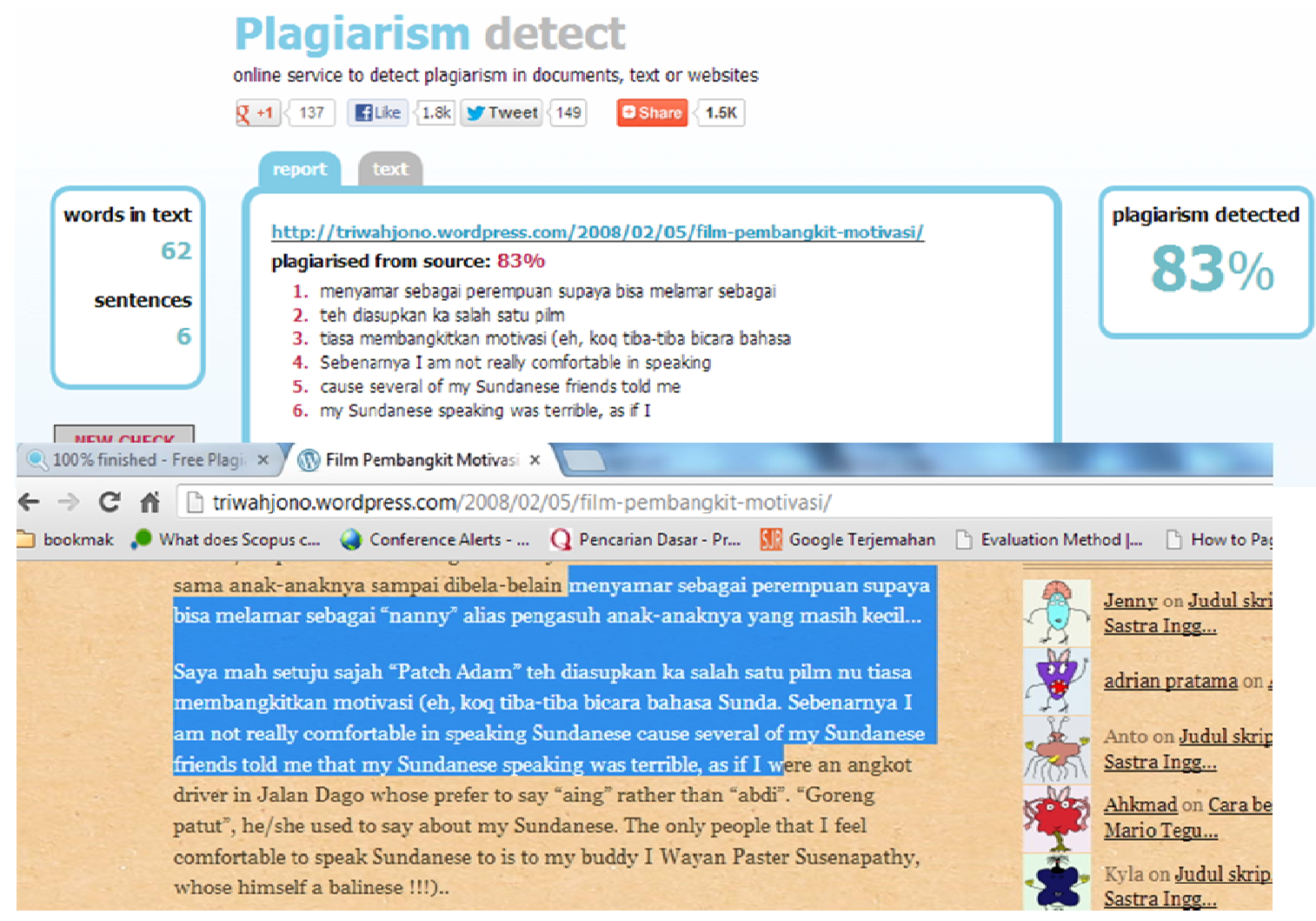

Gambar 2 Salah satu software pendeteksi plagiarisme

(Tridjoko, 2008)

Sebuah model perangkat lunak pendeteksi plagiarisme akan dibangun setelah melalui tahap uji coba dan analisis fitur (berupa laporan teknis/technical report) dari beberapa perangkat lunak pendeteksi aksi plagiarisme.

Tahap selanjutnya adalah simulasi kasus yang akan melalui tahap uji coba beberapa software pendeteksi plagiarisme. Software yang akan diuji coba dikelompokkan menjadi dua bagian. Kelompok pertama berdasarkan ketersediaan source code, yaitu: open source plagiarisme software dan non open source plagiarisme software. Kelompok kedua berdasarkan software platform, yaitu: web based, desktop based, ataupun mobile based. Simulasi kasus dapat diambil sampel dari beberapa artikel ilmiah karya mahasiswa yang sedang menjalani tugas akhir (objek riil). Uji coba terhadap objek riil perlu dilakukan berbarengan dengan proses pengembangan pemodelan software agar tujuan utama dari penelitian ini, yaitu mencegah timbulnya tindakan/aksi plagiarisme tercapai.

Selanjutnya wawancara terstruktur kembali dilakukan terhadap empat pihak yang sudah diwawancarai terdahulu yaitu: Bagian Akademik (SRSC), Bagian Library and Knowledge Center, Research Office, dan Jurusan (pembimbing dan penguji). Survei dilakukan dengan melakukan wawancara terstruktur dengan daftar pertanyaan yang sudah dibuat sebelumnya sehingga didapatkan analisis kesenjangan antara fitur yang diharapkan dan fitur yang sudah dibuat.

\section{HASIL DAN PEMBAHASAN}

Aksi plagiarisme merupakan salah satu masalah fundamental yang sering terjadi di lingkungan akademik. Aksi plagiarisme tidak mutlak disebabkan oleh niat buruk pelaku aksi 
plagiarisme. Ketidaktahuan dan ketidaksadaran pelaku terkadang merupakan penyebab terjadinya aksi plagiarisme di kalangan akademisi.

Studi terdahulu oleh Ramzan, Munir, Siddique, \& Asif (2012) mengenai kesadaran siswa perguruan tinggi di Pakistan terhadap berbagai macam jenis aksi plagiarisme menunjukkan hasil yang cukup mengkhawatirkan. Sebanyak 24\% dari 350 orang responden menyatakan pernah melakukan aksi plagiarisme berupa penyaduran tidak sah dari berbagai sumber referensi tertulis. Mereka tidak mengetahui bahwa tindakan penyaduran yang mereka lakukan merupakan salah satu tindakan yang masuk ke dalam kategori aksi plagiarisme.

Ketidakjelasan pemahaman akademisi mengenai konsep kebijakan plagiarisme tidak hanya dirasakan oleh para akademisi di Pakistan saja. Di Australia, studi terdahulu oleh Ryan, Bonanno, Krass, Scouller, \& Smith (2009) menemukan fakta bahwa para siswa tidak menganggap bahwa aksi plagiarisme sebagai suatu permasalahan yang serius. Menurut para siswa, penggunaan referensi tanpa harus melakukan kutipan dan pengakuan sumber referensi merupakan hal yang biasa dan bukan merupakan suatu aksi kejahatan. Tingkat pemahaman yang rendah terhadap aksi plagiarisme tidak selalu menitikberatkan permasalahan hanya terdapat di kalangan para siswa saja.

Strategi kreatif yang dilakukan para siswa dalam memodifikasi suatu karya publikasi orang lain untuk diklaim sebagai karya sendiri (atau kelompok)-penggunaan sinonim di setiap frasa dan kalimat-terkadang menyulitkan para pengajar untuk memutuskan apakah karya yang dibuat merupakan karya orisinal atau karya plagiat meskipun pengajar mungkin pernah menemukan karya publikasi serupa di internet (Aziz, Hashim, \& Razak, 2012). Hal tersebut dapat dijadikan indikator bahwa tidak semua pengajar pun selalu memiliki pemahaman yang tinggi terhadap aksi plagiarisme.

Deteksi aksi plagiarisme tidaklah selalu mudah untuk dikenali apalagi jika hanya mengandalkan intuisi. Martin (2005) menggunakan bantuan teknologi seperti TurnItin untuk melakukan deteksi aksi plagiarisme di universitas. Namun penggunaan teknologi seperti TurnItin tidak serta merta dapat dijadikan sebagai solusi mutlak. Studi terdahulu oleh Bensal, Miraflores, \& Tan (2013) menyatakan bahwa TurnItin memang alat bantu yang sangat bermanfaat untuk melakukan pendeteksian aksi plagiarisme sebab teknologi tersebut dapat menampilkan tingkat kemiripan (similarity index) yang baik, namun harga sewa lisensi perangkat lunak yang mahal terkadang dapat membebani pihak institusi untuk menggunakan alat bantu tersebut. Oleh sebab itu, sinergi antara siswa, pengajar, dan institusi untuk membangun suatu kebijakan akan antiplagiarisme yang efektif perlu dilakukan demi terciptanya integritas penelitian yang tinggi di kalangan akademisi (Ramzan, Munir, Siddique, \& Asif, 2012).

\section{Model Penelitian}

Kerangka pikir penelitian diwujudkan dalam Gambar 3. Suatu kerangka (framework) antiplagiarisme di suatu institusi pendidikan tinggi dapat diwujudkan dengan meneliti 3 elemen pembentuk. Ketiga elemen ini adalah kesadaran para stakeholder terhadap plagiarisme, pembentukan kebijakan terhadap tindakan plagiarisme, dan pelaksanaan prosedur pemantauan terhadap plagiarisme. Ketiga hal ini tidak dapat dipisahkan dan merupakan fondasi pembentukan integritas akademis di suatu institusi pendidikan tinggi. 


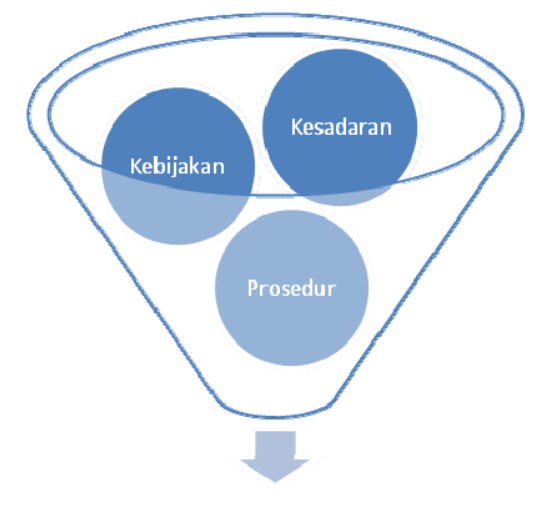

Kerangka Anti Plagiarisme

Gambar 3 Model Penelitian

Berdasarkan masalah dan tujuan penelitian, maka kerangka kuesioner dapat disusun sebagai berikut.

Bagian I : Pendahuluan dan contoh pengisian kuesioner

Bagian II : : Biodata responden.

Bagian III : Pemahaman tidak plagiarisme oleh mahasiswa dan dosen pembimbing. Pertanyaan yang dikembangkan:

1. Seberapa jauh pemahaman mahasiswa dan dosen terhadap plagiarisme, dan pendeteksiannya?

2. Seberapa sering praktik plagiarisme yang dilakukan mahasiswa, seperti menyalin isi buku atau situs web tanpa melakukan rujukan; menyalin hampir keseluruhan sumber, menyontek pada saat ujian dan/atau kuis di kelas; memanipulasi data untuk laporan lab atau laporan proyek; melakukan kerja kelompok yang seharusnya dilakukan sendiri; menggunakan tugas siswa lain yang diaku sebagai tugas sendiri; membayar seseorang untuk melakukan tugas pribadi.

Bagian IV : : Alasan siswa melakukan kecurangan.

Pertanyaan yang akan dikembangkan adalah siswa tidak mengerti aturan merujuk; siswa malas atau tidak mempunyai manajemen waktu yang baik; siswa ingin mendapat nilai yang lebih baik; siswa jarang ketahuan melakukan kecurangan; siswa jarang dihukum/tertangkap sewaktu melakukan kekurangan; bahan/literatur/informasi mudah diakses via Internet.

Bagian V : Dampak Prosedur dan Pedoman Penelitian terhadap tindak plagiarisme. Pertanyaan yang akan dikembangkan:

1. Apakah siswa mendapat petunjuk yang jelas tentang plagiarisme, cara menghindari, dan hukuman bagi siswa yang melakukan pada saat mengerjakan; dosen menjelaskan dan memonitor siswa dalam membuat kutipan dan rujukan dalam karya tulis mereka.

2. Apakah dosen mengecek tugas mahasiswa mengandung plagiarisme.

3. Kejelasan batasan tindakan dan sanksi plagiarisme dalam peraturan perkuliahan.

4. Apakah mahasiswa dan dosen pembimbing telah membaca Kode Etik Akademis Universitas mengenai plagiarisme.

\section{SIMPULAN}

Berdasarkan studi literatur telah diketahui bahwa praktik plagiarisme telah dilakukan di berbagai negara. Praktik plagiarism tidak hanya dilakukan oleh mahasiswa, tetapi juga dosen, peneliti, dan kalangan akademisi lainnya. Praktik plagiarisme juga dilakukan mulai dari tindakan yang tidak disadari, yaitu mengutip dengan tidak menyebut sumber, sampai dengan secara sadar mengambil karya orang lain untuk kepentingan sendiri. 
Dengan makin banyaknya informasi dan data penting yang mudah diperoleh melalui jaringan internet, maka kesempatan melakukan plagiat akan makin besar. Dengan demikian, di kalangan akademik perlu dibuat suatu sistem pendeteksi plagiarisme, baik dilakukan melalui prosedur maupun dibuat suatu perangkat lunak yang mampu mendeteksi plagiarisme.

Berdasarkan masalah penelitian, maka disusun kuesioner yang berisi sejauh mana pemahaman dosen dan mahasiswa terhadap tindak plagiarisme, praktik plagiarisme yang dilakukan mahasiswa, dan alasan melakukan hal tersebut. Kuesioner akan dibagikan kepada mahasiswa dan dosen agar dapat diketahui jenis tindakan dan alasan melakukan plagiarism. Kemudian berdasarkan temuan tersebut akan dilakukan tindakan preventif, yaitu suatu prosedur yang tepat dan perangkat lunak antiplagiarisme untuk mendeteksi tindakan plagiarisme dalam bahasa Indonesia.

\section{DAFTAR PUSTAKA}

Alfikri, Z. F., \& Purwarianti, A. (2012). The construction of Indonesian-English cross language plagiarism detection system using fingerprinting technique. Journal of Computer Science and Information, 5(1), 16-23.

Aziz, J., Hashim, F., \& Razak, N. A. (2012). Anecdotes of plagiarisme: some pedagogical issues and considerations. Asian Social Science, 8(10), 29-34.

Bensal, E. R., Miraflores, E. S., \& Tan, N. C. (2013). Plagiarism: shall we turn to Turnitin? ComputerAssisted Language Learning-Electronic Journal, 14(2), 2-22.

Chao, C.-A., Wilhelm, W. J., \& Neureuther, B. D. (2009). A study of electronic detection and pedagogical approaches for reducing plagiarisme. Delta Pi Epsilon Journal, 51(1), 31-42.

Kementerian Pendidikan Nasional. (2010). Peraturan Menteri Pendidikan Nasional Nomor 17 tahun 2010 tentang Pencegahan dan Penanggulangan Plagiat di Perguruan Tinggi. Jakarta: Kementerian Pendidikan Nasional.

Kurniawati, A., Puspitodjati, S., \& Rahman, S. (2010). Implementasi Algoritma Jaro-Winkler Distance untuk Membandingkan Kesamaan Dokumen Berbahasa Indonesia. Proceeding Seminar Ilmiah Nasional Komputasi dan Sistem Intelejen - KOMMIT. Bali: Universitas Gunadarma.

Liliana, Budhi, G. S., Wibisono, A., \& Tanojo, R. (2012). Pengecekan plagiarisme pada code dalam bahasa C++. Jurnal Informatika, 11(1), 70-78.

Martin, D. F. (2005). Plagiarism and technology: a tool for coping with plagiarism. Journal of Education for Business, 80(3), 149.

Meyer zu Eissen, S., Stein, B., \& Kulig, M. (2007). Plagiarisme Detection without Reference Collections. In R. Decker, \& H. J. Lenz, Advances in Data Analysis and Classification (pp. 359-366). Springer.

Mulyana. (2010). Pencegahan tindak plagiarisme dalam penulisan skripsi: Upaya memperkuat pembentukan karakter di dunia akademik. Cakrawala Pendidikan, 29.

Nugroho, E. (2011). Perancangan Sistem Deteksi Plagiarisme Dokumen Teks dengan menggunakan Algoritma Rabin-Karp. Malang: Universitas Brawijaya. 
Purwitasari, D., Kusmawan, P. Y., \& Yuhana, U. L. (2011). Deteksi keberadaan kalimat sama sebagai indikasi penjiplakan dengan algoritma hashing berbasis N-Gram. Jurnal Ilmiah KURSOR, 6(1), 37-44.

Ramadhanny, F. (2010, April 15). Kasus Plagiarisme Bikin Geger Alumni ITB. detikNews.

Ramzan, M., Munir, M. A., Siddique, N., \& Asif, M. (2012). Awareness about plagiarism amongst university students in Pakistan. High Educ, 64, 73-84.

Ryan, G., Bonanno, H., Krass, I., Scouller, K., \& Smith, L. (2009). Undergraduate and postgraduate pharmacy students' perceptions of plagiarism and academic honesty. American Journal of Pharmaceutical Education , 73(6), 1-7.

Salmuasih. (2013). Perancangan Sistem Deteksi Plagiat pada Dokumen Teks dengan Konsep Similarity menggunakan Algoritma Rabin Karp. Yogyakarta: STMIK Amikom.

Siswadi, A. (2012, March 5). Satu Lagi Kasus Plagiat di Bandung. TEMPO Online.

Tridjoko. (2008, Februari 5). Film Pembangkit Motivasi. Diakses dari http://triwahjono.wordpress.com/2008/02/05/film-pembangkit-motivasi/

Wibowo, A. (2010). Mencegah dan menanggulangi plagiarisme di dunia pendidikan. Jakarta: Fakultas Kesehatan Masyarakat-Universitas Indonesia.

Wijaya, E. (2010, April 16). Plagiarisme dan Solusi Pencegahannya. Diakses dari http://erywijaya.wordpress.com/2010/04/16/plagiarisme-dan-solusi-pencegahannya/

Yahya, I. (2011). Plagiarisme dan [karya] kita. Sarasehan Program Studi Agroteknologi Fakultas Pertanian UPN Veteran (hlm. 1-6). Yogyakarta: UPN Veteran. 